\title{
HET OUDE TESTAMENT EEN OOSTERSCH BOEK VOOR WESTERSCHE MENSCHEN')
}

De doorsnee Bijbellezer realiseert zich niet dat in de boven dit opstel staande titel een probleem schuilt. Het probleem ligt in de tegenstelling Oostersch-Westersch. Het Oude Testament is in het Hebreeuwsch geschreven en het Hebreeuwsch is een Oostersche taal, en de afstand tusschen die twee is zeer groot. Elke in Westersche taal overgezette tekst van het Oude Testament verschilt van den Hebreeuwschen tekst. Dat verschil is van dien aard dat tal van fijne trekjes en teere gedachten van den Hebreeuwschen tekst voor den ongeschoolden Zuid-Afrikaanschen of Nederlandschen lezer verborgen blijven. Het verschil is zoo groot als dat van het Oude Oosten en het nieuwe Westen, voor zoover dat ook in de taal zijn uitdrukking vindt. De aandachtige lezer die verschillende Westersche vertalingen met elkaar vergelijkt, moet het opvallen dat tusschen die vertalingen dikwijls een groot verschil bestaat, soms zóó groot dat de zin geheel van beteekenis verandert. En als hij niet bekend is met de eigenaardigheden van het Hebreeuwsch, zal hij zich verwonderd afvragen, waaraan die dikwijls ver uiteenloopende vertalingen te wijten zijn en hoe het mogelijk is dat een en dezelfde Hebreeuwsche tekst zoo verschillend kan worden vertaald? En ook: welke van die verschillende vertalingen nu wel de juiste is?

Het hier aangeduide verschil zit - maar niet alleen - in de $t$ a a 1 . Het Hebreeuwsch staat, als taal, door woordvorming en constructie, zoover van de Westersche talen af, dat een geheel letterlijke vertaling, in welke Westersche taal ook, telkens onverstaanbaar zou zijn. Immers het Hebreeuwsch kent niet onze buigingsvormen van naamwoorden, noch onze vervoegingsvormen van werkwoorden en de syntactische verhoudingen worden uitgedrukt op een wijze die, letterlijk weergegeven, in het Nederlandsch of Zuid-Afrikaansch onverstaanbaar zou zijn. Daaraan is het toe te schijven dat noch de Statenvertaling, noch de nieuwe Zuid-Afrikaansche vertaling een letterlijke weergave van het Oostersch Hebreeuwsch zijn, maar dat ze naar eigen constructies hebben gezocht. Daar ligt de oorzaak van de vaak zoover uiteenloopende vertalingen van den Hebreeuwschen tekst. De Nederlandsche Staten-Vertaling (verschenen in 1637) vertaalt zoo letterlijk als maar eenigzins mogelijk is, soms tot onverstaanbaar wordens toe (zie Job 28: 4, Psalm 141: 6 en 7 en vele andere plaatsen). Het Oude Testament is nu eenmaal een

1) Voor den Oud-Testamenticus van professie bevat dit artikel niets nieuws. Voor anderen die zich voor deze vragen interesseeren, misschien wel. 
Semietisch, dus Oostersch boek en wij zijn Westerlingen. De kloof tusschen die twee is breed en door een nog zoo goede vertaling niet te overbruggen. Wij zijn anders dan de schijvers van het Oude Testament, niet alleen in zeggen, maar ook in denken en voelen. Ik ga dat verduidelijken, maar eerst nog een opmerking vooraf.

Israël woonde als een der kleinste volken in een der kleinste landen van Voor-Azië, en dit gebied werd beheerscht door de groote, zich over geheel Voor-Azië uitstrekkende eeuwenoude, gemeenschappelijke kultuurvormen van Babylonië, Assyrië en Egypte, in wier gebied het Israëlietisch volk betrekkelijk pas zeer laat binnendrong (15e eeuw v. Chr.). Deze machtige oude kultuurwereld werd nu de historische achtergrond van Israëls geschiedenis en literatuur. En wij kunnen Israëls geschiedenis en literatuur niet begrijpen zonder kennis van dien achtergrond, want Israëls kultuurbezit is uit dien achtergrond ontsproten. Dat geldt ook van de taal der Israëlieten: het Hebreeuwsch. De Hebreeuwsche literatuur draagt in zinsbouw, constructie, wijze van zich uitdrukken, en uitbeelding van abstracte begrippen alle kenmerken van die groote kultuurwereld.

Maar hoezeer Israël ook de kenmerken draagt van een onderdeel te zijn van die groote Voor-Aziatische kultuurwereld, in één opzicht heeft dit volk zijn zelfstandigheid bewaard tegen alle invloeden van buiten in: in zijn godsdienst. Temidden van die groote polytheistische volken met hun natuurgoden en talrijke godinnen, hun natuurdienst en bijgeloof, hun hemelvader en aardemoeder, die samen het natuurleven voortbrachten, en waar naast elken god een godin werd vereerd, weet Israël zoo weinig van een vrouwelijke godheid, dat het Hebreeuwsch zelfs geen woord heeft dat ,godin" beteekent. Terwijl het geheele Oosten vol was van godenbeelden, heeft Israël nooit een beeld van zijn God Jahwe gekend. Sommigen meenen dat in Ex. 20: 4 en 5 het maken van een beeld van Jahwe wordt verboden. Als dat waar was, dan zou dat beteekenen dat in Israël wèl godenbeelden werden vereerd, in elk geval dat ze bestònden, want alleen iets dat bestaat, wordt verboden (wat niet bestaat, behoeft niet verboden te worden). Wat in Ex. 20 wordt verboden is het maken van beelden van hetgeen boven in den hemel is, of van wat beneden op de aarde is of van wat in de wateren onder de aarde is. Nu onderscheiden de Babyloniërs duidelijk tusschen het terrein van den hemelgod (Anoe), het terrein van den aardegod (Enlil) en het terrein van den onder de aarde wonenden god (Ea). Het betreft dus beelden van de Babylonische natuurgoden. Van Israëls God (Jahwe) heeft Israël nooit beelden gemaakt.

Ook in 1 Kon. 12: $28 \mathrm{vv}$. is geen sprake van een Jahwebeeld. Die twee kalveren die Jerobeam maakte, waren niet anders dan het voetstuk, piedestal, van de daarop te stellen afgodsbeelden. De Oostersche volken plachten n.l. dierenbeelden te gebruiken als voetstuk voor hun godenbeelden en Jerobeam bootste dat na. Maar een Jahwebeeld stond niet 
op dat voetstuk. Dat kon ook niet want Deut. 4:15-24 staat duidelijk dat Israël de gedaante van zijn God nooit had gezien en dus niet kende, zoodat het maken van een beeld van hun God niet mogelijk was. Israël heeft nooit een Godsbeeld gehad. Dat is een geweldig argument voor de religieuze zelfstandigheid van Israël te midden der heidenwereld! Israëls godsdienst bewaarde zijn officieele onafhankelijkheid in religiosis tegenover het geheel heidensche Oosten en beschouwde Jahwe als de eenige wereldgod; het bleef het eenige monotheïstische volk der geheele oudheid, en heeft dat tegen alles in gehandhaatd. Israël voelde zich Gods uitverkoren volk.

Maar overigens is dat kleine volk een onderdeel van de ééne groote Voor-Aziatische kultuur. De Hebreeuwsche literatuur draagt dan ook in constructie, zinsbouw, wijze van uitbeelding van gedachten en abstracte begrippen alle kenmerken van die groote kultuurwereld. En die kultuurwereld had eenige kenmerken die specifiek van de onze onderscheiden zijn. Ik noem enkele, speciaal die waarin het oude Oosten van het hedendaagsche Westen verschilt en waarvan de kennis noodig is om allerlei uitingen van het Oude Testament te verstaan.

Het eerste is dit: Wij stellen bij schijvers en dichters prijs op e ige $n$ visie en eigen dictie. Wij haten het cliché, vooral, in de literatuur. De dichter, de schijver, de spreker, moet iets „eigens", iets ,„aparts" zeggen of schrijven om te boeien. Geen traditioneele, afgezaagde versleten termen. Of de vorm ò de inhoud moet ,origineel" zijn om hoorders of lezers te boeien. Vooral in de dichtkunst geldt dat. Dichters met eigen „kijk" op de dingen of eigen expressie gelden als de beste. In het Oude Oosten en ook in het Oude Testament is dat anders. Daar hullen nieuwe waarden zich steeds in oude woorden. Alleen door de poort van het oude woord kunnen nieuwe waarden ingang vinden. Of zulke oude woorden werkelijk nieuwe waarden vertegenwoordigen. blijkt uit de omgeving waarin ze voorkomen. Men beminde het cliché, de monotonie, de eenvormigheid. Er bestond in den tijd van het ontstaan van het Oude Testament reeds een geweldig breede Babylonische, Assyrische en Sumerische literatuur, die diezelfde monotonie vertoont, datzelfde cliché-karakter, dat den geest van het oude Oosten kenmerkt en. waarvan we pas na langdurige oefening en geduld de schoonheid kunnen beleven. De $119 \mathrm{e}$ Psalm b.v. vertoont datzelfde karakter in hooge mate.

Een tweede eigenaardigheid der oud-Oostersche literatuur is haar a n o n'i m it e it. De namen der schrijvers zijn bijna altijd onbekend. En wat weten we van de schrijvers van verre de meeste boeken van het Oude Testament, de profeten en sommige Psalmen uitgezonderd? Ook hierin blijkt duidelijk hoezeer de enkeling alleen wordt gezien als onderdeel van de groep waartoe hij behoort. $Z_{\mathrm{ijn}}$ naam blijft achterwege. Het milieu domineert; de individu is uit het volksgeheel nog onvolkomen losgemaakt, behalve bij enkele prominente figuren als Mozes, Elia en 
ook de koningen. Met deze anonimiteit hangen samen verhalen als II Sam. 24, waar 70,000 omschuldigen omkomen om een misdaad die ze niet bedreven hebben, en Joz. 7 waar wordt verhaald dat om Achans zonde zijn gansche geslacht wordt uitgeroeid. Zulke dingen die wij tijdens de Duitsche bezetting ook hebben beleefd, doen ons schrikken en tasten ons rechtsgevoel aan. In het oude Oosten gold het als normaal en vanzelfsprekend. Eeuwen later, in den tijd der ballingschap, toen Israël zich meer begon los te maken van de oud-Oostersche zeden en meer bewust werd van eigen geestelijk bezit en vooral de persoonlijke verantwoordelijkheid meer op den voorgrond kwam, werd ook dat anders. Ezech. 18:20 geeft uitdrukking aan deze meer persoonlijke verantwoordelijkheid: de ziel die zondigt zal sterven, de zoon zal niet dragen de ongerechtigheid des vaders enz. Maar de maatstaf voor goed en kwaad ligt toch nog bij de groep waar de booze daad wordt afgekeurd door het karakteristieke: zoo doet „men" niet!

Een derde eigenaardigheid der Oud-Oostersche literatuur blijkt in het geschiedverhaal dat het karakter draagt van een schilderij, niet van een foto. In dit verband is misschien het verschil tusschen deze twee het best zoo te zeggen: De fotograaf geeft alleen de gegeven werkelijkheid, hij ,,waardeert" niet, maar beschrijft alleen; hij geeft kritiekloos op de gevoelige plaat weer wat hij aanwezig vindt. De schilder werkt anders: Hij zal opzettelijk een onderdeel negeeren en een ander onderdeel sterk naar voren brengen, opdat de hoofdgedachte die hij wil uitdrukken te duidelijker uitkome. Het is hem niet te doen om de uiterlijke omlijningen, maar om de idee, het wezen, de innerlijkheid van zijn object, welks schoonheid of waarheid hij in het licht wil stellen. Een schilder wil niet ,objectief" zijn, hij is prediker. Zoo is ook de Oosterling prediker als hij wat vertelt; het is hem niet te doen om de bloote feiten, maar om het leven dat in die feiten klopt, om de leering die hij er in ziet, en die hij anderen wil mededeelen. Willen we dus een Oostersch dus ook een Oud-Testamentisch verhaal verstaan, dan moeten we doordringen tot de bedoeling waarmee de schijver dat verhaal vertelt, d.w.z. tot de prediking die hij er in heeft gelegd. Het gaat dus niet om het verhaal zelf of om de geschiedenis als bloot feit, maar om de leering die er in ligt. M.a.w. het Oostersch verhaal is geen foto maar een schilderij. De aandachtige Bijbellezer vindt in vele Bijbelverhalen tal van kleine trekjes die onbeteekenend schijnen en niet alleen overbodig maar zelfs storend aandoen en die toch soms een belangrijke functie in het verhaal bekleeden. Geen enkel trekje is waardeloos.

Een andere eigenaardigheid van het oud Semietisch taalgebruik is het sterk beeldend karakter der woorden. Woorden die bij ons zuiver abstracte begrippen aanduiden (als haat, liefde, toorn, waarheid enz.) hebben in het Hebreeuwsch een sterk concrete tastbare achtergrond. Een letterlijke vertaling in een Westersche taal is dan feitelijk onverstaanbaar. Ik bepaal mij tot een paar voorbeelden. In Ezra 9:8 staat 
in de Statenvertaling: „is ons genade geschied van den Heere om ons een $\mathrm{n}$ a g e $\mathrm{l}$ te geven in zijne heilige plaats om onze oogen te verlichten." De Zuid-Afrikaansche vertaling heeft: „om ons 'n pen te gee in sy heilige plek sodat onse God ons oë verhelder." Voor den gewonen Bijbellezer is het niet duidelijk wat daar wordt bedoeld. Het daar gebruikte woord j a t e $\mathrm{d}$ beteekent inderdaad nagel of pen. Maar bedoeld is een pen waarmee de koorden van de woontent in den grond worden vastgestoken. Als de vertaler den $z$ in van deze gedachte wil uitdrukken dan moet men vertalen: „om ons een rustplaats of woonplaats te geven." En het volgende: ,om onze oogen te verlichten" zou moeten worden vertaald: „om ons blijdschap te geven."

Is zulk een vertaling niet te $\mathrm{v} r \mathbf{i} \mathbf{j}$ ? Dat is een moeilijke vraag. De Bijbel moet zoo letterlijk mogelijk worden vertaald, maar niet tot onverstaanbaar wordens toe. Een vertaling moet immers dienen om den tekst voor de lezer in zijn eigen taal verstaanbaar te maken. De Statenvertaling is te letterlijk, waardoor de zin onverstaanbaar wordt. De Zuid-Afrikaansche vertaling is reeds beter en ook de thans in Amsterdam in bewerking zijnde vertaling. Maar toch zijn ook deze naar mijn meening, nog tè letterlijk en is de verstaanbaarheid aan de letterlijkheid opgeofferd.

Geestelijke gewaarwordingen als liefde, haat, barmhartigheid enz. lokaliseert de Oosterling in het menschelijk lichaam en geeft zulke gewaarwordingen weer door woorden als: ingewanden, moederschoot enz. B.v. Spreuken 12:10 staat in het Hebreeuwsch letterlijk: de ingewanden der goddeloozen zijn wreed. De Staten-Vertaling geeft den zin juist weer door te vertalen: de barmhartigheden der goddeloozen zijn wreed. De Zuid-Afrikaansche vertaling blijft dichter bij het oorspronkelijk door te vertalen: gemoed. In I Kon. 3:26 (het verhaal van Salomo's rechtspraak) wil de moeder van het levende kind het sparen, want, zegt de Staten-vertaling: haar ingewand ontstak over haar zoon. De Zuid-Afrikaansche zegt: haar binnenste was ontroerd. Dat is beter maar minder letterlijk.

Waar de Hebreeër zegt: iemand om een gunst verzoeken, zegt hij: iemands aangezicht aaien of streelen. Ps. 45:13 staat in de Statenvertaling; De dochter van Tyrus zal uw aangezicht met geschenken smeeken. Dat is ongelukkig Nederlandsch, een poging om al te letterlijk te vertalen. De Zuid-Afrikaansche beter: met geschenke zal hulle u guns soek. Hetzelfde in Spreuken 19:6 en Job 11:19. Op beide plaatsen staat in het Hebreeuwsch: het aangezicht streelen. Vanwaar die eigenaardige uitdrukking? Bij dringende verzoeken placht men wel met de linkerhand den baard te vatten en met de rechterhand de wang te aaien van hem wien men om een gunst verzocht.

Het is bekend hoe Joden door houding, gebaar en zekere bewegingen hun gevoelens plegen uit te drukken. Natuurlijk vinden we de sporen daarvan in het Oude Testament. In Ps. 35:19 en Spreuken 10:10 
wordt de gedachte leedvermaak uigedrukt door: knippen met de oogen. In Spreuken 16:30 is het de uitdrukking voor: listen beramen. In deze verzen kan de letterlijke vertaling worden volgehouden omdat uit den contekst de beteekenis voldoende duidelijk is.

Ook de opzettelijke beeldspraak is vaak plastisch teekenend. Hozes 7: 8 staat: Efraim is een koek die niet omgekeerd is; d.w.z. aan den eenen kant aangebrand, aan den anderen kant niet gaar. Daarmee wordt aangeduid Efraïms dubbelhartigheid. Dat de zonden der vaderen worden bezocht aan te kinderen wordt zoo gezegd: de vaderen hebben onrijpe druiven gegeten, daarom zijn de tanden der kinderen stomp geworden (Jer. 31:29; Ezechiël 18:2).

Het verschil tusschen Oostersche en Westersche wijze van spreken gaat nog veel verder dan alleen in bepaalde zegwijzen. Er zijn woorden van centrale beteekenis die voor de Semietische oudheid een gansch andere beteekenis hebben dan voor ons. B.v. het woord wonder. Naar Westersch spraakgebruik is een wonder iets dat boven het natuurlijk gebeuren uitgaat. Wat gebeurt volgens de natuurwetten, al is het nog zoo opvallend, noemen wij geen wonder. Zoo noemen wij het gebeurde vlgs. Joz. 10: 11, waar Israëls vijanden door groote hagelsteenen worden gedood, geen wonder (zonder natuurlijk te ontkennen dat het een daad van God was); maar als in vs. 12 wordt verhaald dat de zon een geheelen dag aan den hemel stil stond, dan noemen we dat wèl een wonder, want dat gaat wèl boven het natuurlijk gebeuren uit. Dat onderscheid kent het oude Oosten niet want het kent niet een zelfstandig, volgens bepaalde wetten plaats hebbend "natuurlijk" gebeuren, maar ziet alles als rechtstreeksche werking van God. Thomas van Aquino formuleerde het zoo: een wonder is het overslaan van de causae secundae. Dat verschil tusschen wat gebeurt volgens het geregeld beloop der natuur en dat wat daarmee in strijd is, kende de Oosterling niet. Immers voor hem is God de bewerker van a l wat gebeurt, natuurlijk en bovennatuurlijk. Zoo worden b.v. in Job 37:2-14 stormwind, bliksem, sneeuw, regenstroomen, ijs enz. wonderdaden Gods genoemd. De wonderwerken Gods waarvan sprake is in Ps. 107:15, 21, 24, 31 behooren vlgs. ons spraakgebruik tot de sfeer van het natuurlijk gebeuren. Wij gebruiken het woord wonder ook wel in overdrachtelijken zin van belangwekkend, geweldig, maar niet in den technischen zin waarvan hierboven sprake was. De Hebreeër noemt wonder alles wat hem $\mathrm{v}$ e $\mathrm{r}$ - w o nde $\mathrm{r}$ - $\mathrm{t}$ : de sterrehemel bij nacht, de walvisschen in den oceaan, de onstuimige golven der zee.

Maar het verschil tusschen Oostersche en Westersche wijze van zien en zeggen reikt nog verder, o.a. op het gebied van cijfers en getallen. Deze zijn voor ons niet anders dan aanduidingen van bepaalde hoeveelheden. In het Oude Oosten en dus ook in het Oude Testament hebben cijfers en getallen een eigen inhoud en zelfstandige beteekenis. $\mathrm{Bij}$ sommige getallen is dat zoo sterk, dat het hun gebruik beheerscht. B.v. 
bij de getallen 3, 4, 7 en 12. Dat zijn geen bloote cijfers maar kosmische grootheden. Als voorbeeld nemen we het getal 7. In het Assyrisch heet dat getal sibittoe, waarvan het stamwoord beteekent: vol zijn, compleet zijn, en als substantief: volheid, geheelheid, en zelfs: a 11 e s. Het getal 7 wordt dus toegepast op dingen waarvan men zeggen wil dat ze ,af", dat ze "compleet" zijn. Het is een totaliteitsgetal. De kosmos heeft in het Oude Oosten 7 sferen, evenals de hemel en de onderwereld. De Babyloniër, die natuurlijk niet alle landen kent, teekent toch een wereldkaart waarop hij 7 landen teekent, d.w.z. a 11 e landen. De levensboom, welks vrucht eeuwig leven geeft, heeft 7 of tweemaal 7 takken, waardoor wordt angeduid dat hij àlle leven voedt. Zoo wordt ook de alles verlichtende zon in Egypte afgebeeld met 7 of twee maal 7 stralen. De Babylonische goden worden aangeduid als de ,zevenheid", d.i.: alle goden, en van de overweldigende massa daemonen heet het: 7 zijn ze, 7 zijn ze, tweemaal 7 zijn ze! In dit laatste voorbeeld is het duidelijk dat 7 niet is 4 plus 3 , dus niet een gewoon cijfer. In het Oude Testament vinden we hetzelfde. Als de wereld in 7 dagen wordt geschapen, dan wordt daardoor uitgedrukt dat het een volkome n schepping is. Het Hebr. substantief sjabbat voor den zevenden dag beteekent dan ook niet in de eerste plaats rustdag, maar (dag der) volkomenheid, compleetheid en het verbum sjabat beteekent eig. niet r uste n, maar gereed zijn, klaar zijn, voltooid zijn. De Syriër Naäman die melaatsch was, moest zich 7 maal wasschen in de Jordaan om geheel rein te worden (II Kon. 5:10 en 14). Als Jobs vrienden hem in zijn lijden bezoeken, zitten ze 7 dagen sprakeloos, d.i.: ze zijn geheel verslagen door zooveel leed. Simsons groote kracht ligt in zijn lange haren, maar als hem 7 lokken worden afgeschoren, wordt hij machteloos (Richt. 16: 17 vv.). Een eed zweren heeft in het Hebreeuwsch eig. „zich bezevenen”, d.i. de sterkste belofte of getuigenis afleggen. Zich 7 maal voor iemand nederbuigen beteekent: volkomen onderwerping (Gen. 33:3). Iemands misdaad vergeven is pas volkomen als het 7 maal of 70 maal 7 maal geschiedt (Matth. 18:22). Om Jericho te doen vallen, moeten 7 priesters de stad 7 maal omtrekken.

$W_{i j}$ moeten zulke uitlatingen en wijzen van zien niet een spelen met cijfers noemen, want voor het Oude Oosten is het dat niet. Het gaat hier om het $\mathrm{kade} r$ waarin het aardsch gebeuren wordt gezien en beoordeeld. In al deze gevallen worden de feiten gezet in een kosmisch kader van de zevenheid. Wat in dat kader wordt gezet, heeft daardoor zijn waarheid bewezen en wordt er geloofwaardig door. En deze voorstellingswijze staat niet zoover van onze denkvormen af als wij op het eerste gezicht zouden meenen. 'Immers wij doen eigenlijk hetzelfde, met dit verschil dat wij een ander kader gebruiken. Wat voor den ouden Oosterling het kosmisch kader was, is voor ons het logisch kader van het causaal verband. Ook voor ons hangt de innerlijke waarschijnlijkheid van het verhaalde af van de vraag of het beantwoordt aan zekere 
logische eischen. Alleen wat logisch en causaal aanvaardbaar is, wordt als waar erkend. In die twee verschillende maatstaven ligt het verschil tusschen Oostersch en Westersch denken. En dat verschil rust weer op een diepgaand onderscheid in wereldbeschouwing. De Oosterling gaat uit van de eenheid van den kosmos en leidt daaruit aard en wezen van de enkeldingen af. Wij kunnen dat niet, omdat wij aard en wesen van den kosmos niet kennen, zoodat deze als uitgangspunt niet dienen kan. De Oosterling kent wèl den kosmos als geheel - méént dien in elk geval te kennen en leidt daaruit deductief al het andere af. Deze karakteristieke beschouwingswijze - die ik natuurlijk met Westersche bewoordingen moet aanduiden -is samen te vatten in de formule: het deel representeert het geheel. Alles is kosmos, macrocosmos of microcosmos. In elk onderdeel weerspiegelt zich het geheel. Alles hier op aarde "correspondeert" met wat aan den hemel gebeurt. De 7 hemelsferen en de 7 planeten hebben hun aardsche correspondentie in de 7 klimaten, de 7 landen, de 7 kleuren, de 7 metalen enz.

Al deze voorstellingen vinden ook in het Oude Testament hun weerspiegeling. Niet in dezen zin dat de Oud-Test. schrijvers deze dingen zouden hebben ,,bestudeerd", maar ze zijn geboren en hebben geleefd in een wereld waar deze dingen golden; zoo werden ze hun.onbewust eigendom, de sfeer waarin ze dachten en de taal waarin ze zich uitdrukten. Zoo komt het dat de bovenaangeduide voorstellingen openlijk of versluierd ook in het Oude Testament aan den dag treden. Het merkwaardige daarbij is dat voorzoover dergelijke voorstellingen in strijd kwamen met het zuivere Jahwisme, ze een bestrijding vonden als afgoderij (Jes. 47:13; Job 38:33; Am. 5:26; II Kon. 23: 5 enz.).

Utrecht

Н. Тн. Oвbink. 